\title{
Enhancing cross-agency collaboration through the use of a universal discovery instrument: Introducing the Life and Career Assessment Matrix
}

\author{
George P. Tilson, Jr. \\ Tilson \& Diaz Solutions, Inc., 7533 Carroll Avenue, Takoma Park, MD 20912, USA \\ Tel.: +1 240498 1956; E-mail: George@TilsonDiazSolutions.com
}

Revised/Accepted November 2015

\begin{abstract}
.
BACKGROUND: When it comes to discovery - learning all we can about a career seeker's passions, aspirations, talents, and support needs - approaches and instruments abound. While there are many excellent resources available to the field, there is an ongoing challenge: often multiple entities (schools, service providers, and vocational rehabilitation agencies) are supporting the same person and using tools that may be duplicating their efforts to gather useful information, or worse, providing conflicting information.

OBJECTIVE: In an era where collaboration and communication across agencies are vital, this article introduces an instrument for consideration. The instrument described is referred to as the Life and Career Assessment Matrix (LCAM), which is an expanded version of the positive personal profile.

CONCLUSION: This tool provides a common framework that can be used by self-advocates, their personal supporters, educators, vocational rehabilitation counselors and adult service providers alike to help all partners discuss and develop plans and activities leading to excellent work experiences, paid employment, and community inclusion.
\end{abstract}

Keywords: Career, transition, assessment, collaboration, discovery, inclusion

\section{Introduction}

In the grand scheme of things, those of us in the fields of education, human service, and workforce development are "opportunity brokers." We connect people with disabilities - at all ages and life circumstances - to opportunities for meaningful and valued lives, within the arenas of work, lifelong learning, independent living, and community membership and contribution. To do this we must be oriented to what Zander and Zander (2000) call "the art of possibility." One might assume that readers of the Journal of Vocational Rehabilitation would be concerned almost exclusively with the work lives of the people we serve. Yet we know that careers encompass the totality of our life experiences: our education, training, work history; our social ties and relationships; our avocations and life adventures (Bolles, 2010). As Paul Jun puts it: "the trajectory of our careers is one of the great manifestations and reflections of our inner potential, desires, and talents. Our work history can read like the chapters of a book: Each page tells a story about our struggles, moments of luck, growth and change $(2015$, p. 1)." Every person for whom we advocate is, like us, on a nonlinear path of discovery: learning about ourselves, 
becoming aware of - and exploring - new ventures; gaining skills through formal training and informal experience, taking supported risks, failing, growing - and in the process learning even more about who we are and what we are made of. Several authors support the notion that career development should be "purpose-centered" (Kosine, Steger, \& Duncan, 2008) and strength-based (Smith, 2006). Hence our role is to help people discover those strengths and to form interdependent relationships that are the foundation of adult success. The instrument described in this article is intended for all professionals who envision themselves as opportunity brokers.

\subsection{Conceptualization of the Life and Career Assessment Matrix instrument}

Developed by the author in collaboration with Sandra J. Miller, Delaware Division of Vocational Rehabilitation, The Life and Career Assessment Matrix (LCAM) is a 20-page expanded version of the Positive Personal Profile (PPP) (Tilson \& Cuozzo Stern, 2001). The PPP (Fig. 1) has been disseminated widely across the country over the intervening years, and adapted and adopted as an informal discovery tool by school systems, adult service providers and key state-level agencies mandated to work together on transition of youth with disabilities from school to adult life. For example, in the rural community of Emmetsburg, Iowa, the PPP (referred to as "P3") has been implemented for all students, with and without disabilities, from 5th grade through graduation. Teachers, counselors, students, parents, and others have found the profile to be extremely beneficial in engaging students and helping teachers learn more about them. This information is useful in preparing the youth to be active participants in the IEP process and for identifying and supporting appropriate work-based learning opportunities (T. Griggs, personal communication, November 6, 2015). The LCAM provides built-in prompts and mechanisms for the individual and his supporters to document critical career-related experiences, as well as reflections on those experiences. In Delaware, the LCAM is currently being piloted within the Department of Education, the Division on Developmental Disabilities Services and the Division of Vocational Rehabilitation. The LCAM developers presented this instrument during a pre-conference seminar at the 2015 International APSE conference in Philadelphia attended by cross-agency representatives. Evaluation feedback from the participants indicated high enthusiasm and endorsement of the instrument. In this article the author describes the key features of the LCAM, and cites literature that reinforces their importance and relevance.

\subsection{Intent of the instrument}

The LCAM has been designed to be an informal person-centered instrument appropriate for anyone from those who will go on to higher education to those who plan to enter employment as they transition from high school - to those who may need substantial supports in their everyday lives. While it was first envisioned as a tool to assist people with disabilities, the reader will likely see that it can be useful for those who may not have a disability, or who may face life obstacles other than disability. We do hope that it helps people create a vivid picture of their strengths, preferences, interests and aspirations, along with a record of pivotal life experiences and their challenges, needs for support, and effective solutions or accommodations to address each challenge. The data gathered through the LCAM can subsequently be used to inform the development of an Individual Education Program Plan (IEP), Individual Plan for Employment (IPE), Individual Service Plan (ISP), or any other plan of action. Perhaps more importantly, it can help youth and adults prepare to actively participate in meetings where they are the topic of discussion. It can also be a workbook of sorts to help individuals as they develop resumes, prepare for interviews, and even essays for college applications.

It should be noted that, like the positive personal profile, the LCAM is a mechanism for capturing information from observations and interviews. It can also be a way of summarizing data from myriad other sources and assessment instruments. In a sense, it is a means of consolidating and highlighting critical information about the individual.

\subsection{Support from the literature}

The key questions to be answered are: What do I want in my life, and what do I have to offer the world? What experiences have I had, what do I do well - and what are my reflections on those life experiences? In what areas do I need help - and do I know how to access the assistance I may need? These questions are daunting for many of us, particularly youth with disabilities whose outcomes have been welldocumented in the National Longitudinal Transition 


\section{Positive Personal Profile}

George Tilson \& Lisa Cuozzo Stern, 2001

Name:

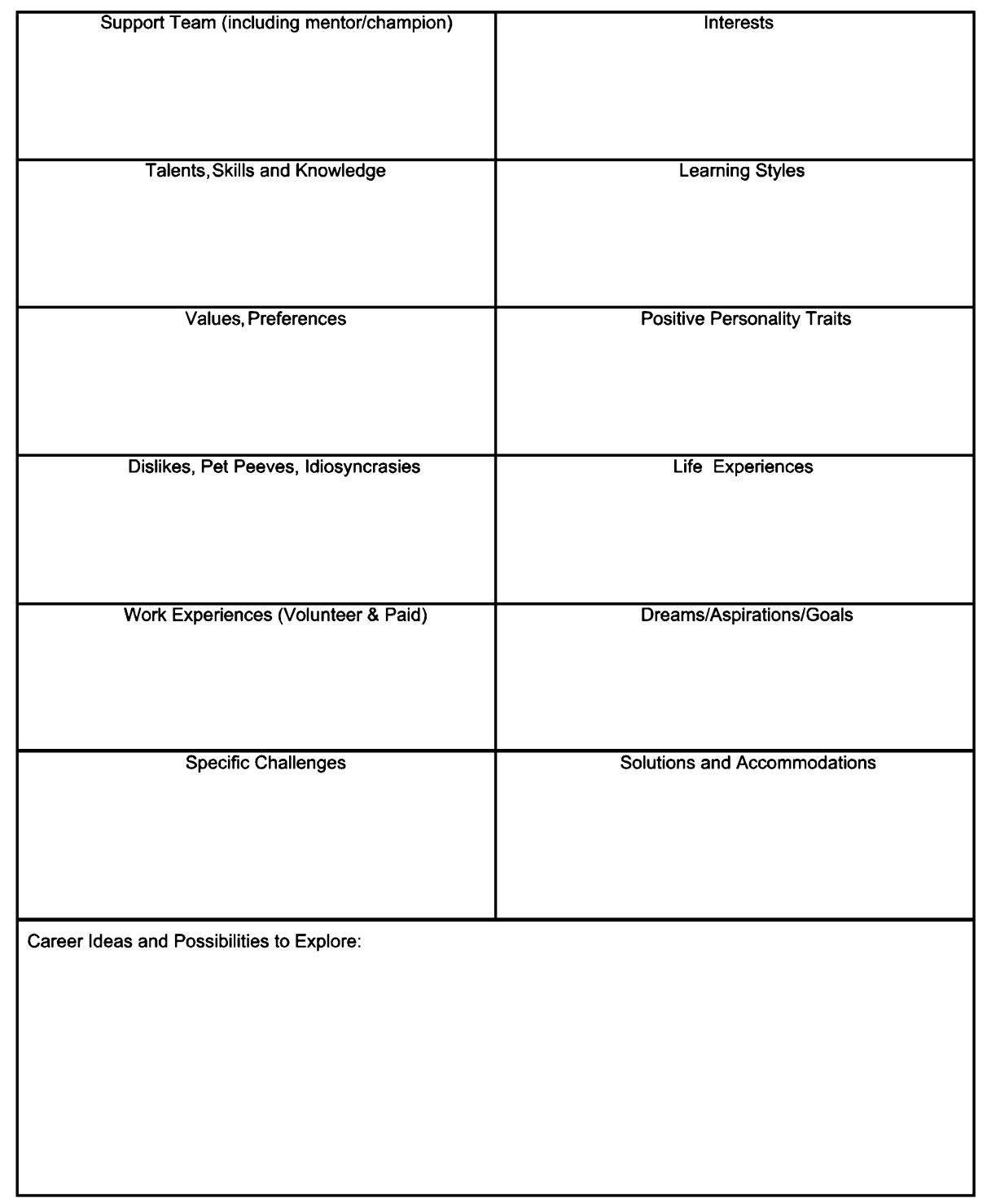

Fig. 1. The Positive Personal Profile.

Study (NLTS) (Newman et al., 2011), and the work of Carter, Austin, and Trainor (2011), Gonzalez, Rosenthal, and Kim (2011), Horvath-Rose, Stapleton, and O'Day (2004), Rangarajan et al. (2009), Simonsen and Neubert (2013), Tilson and Hathaway (2010), among many others.

Although steady progress has been made over the years, youth with disabilities, overall, still experience low rates of competitive employment (Honeycutt, Thompkins, Bardos, \& Stern, 2015). In a study of a subset of 2,900 young adults with disabilities from the 11,000 youth in the NLTS- 2 database, employment rates were reported as ranging from $40-60 \%$ (Sima, Wehman, Chan, West, \& Luecking, 2015). The U.S. Department of Education (2010) found that the employment rate among youth with disabilities aged 17 to 21 was $57 \%$ compared to their peers without disabilities (66\%). Many vulnerable youth and young adults are at significant risk of being left out of the promise of meaningful adult engagement, without 
resources, champions, appropriate interventions or services (Tilson, 2015). Trainor and her colleagues refer to the obligation within our multi-disciplinary fields to help these marginalized populations to maximize their opportunities (Trainor, Lindstrom, Simon-Burroughs, Martin, \& Sorrells, 2008).

Factors promoting or hindering the achievement of desired post high school outcomes of youth with disabilities have been identified in the literature by numerous authors, among them Achterberg, Wind, and Frings-Dresen (2012) and Test et al. (2009) who pointed to 16 major predictors of adult success for these youth.

One of these predictors has been identified as interagency collaboration. Under the IDEA, formal partnerships among education and multiple agencies serving people with disabilities are mandated (Provenmire-Kirk et al., 2015). Yet collaboration, as the saying goes, is easier said than done. Complications abound: differing definitions of disability between the entitlement and eligibility systems, funding sources that are often tightly bound to their "silos," policies that are oddly juxtaposed and processes that are cumbersome (The Study Group, 2007). Several authors have pointed to gaps in communication across key agencies because of databases that will not allow for data sharing, hence hindering collaborative data-driven decision-making (Brewer et al., 2011; Dresser et al., 2009; Landmark, Ju, \& Zhang, 2010; Noonan, McCall, Zheng, \& Gaumer Erickson, 2012; Noonan, Morningstar, \& Erickson, 2008; Oertle, Plotner, \& Trach, 2013; van Velzen, van Bennekom, Sluiter, \& Frings-Dresen, 2015). Provenmire-Kirk and her colleagues (2015) have developed and are in the process of evaluating a crossstakeholder model called CIRCLES: Communicating Interagency Relationships and Collaborative Linkages for Exceptional Students. They point to the need for gathering ample, frequent and relevant information about the individuals being served. The LCAM is intended to be a resource that schools and agencies can use in tandem, as a means of gathering and sharing information about individuals with whom they are all working. A common instrument would be a way to enhance communication, which in turn drives genuine collaboration.

\section{Components of the LCAM}

The LCAM is comprised of 10 sections: (1) Community, (2) Interests, (3) Talents, (4) Positive Personal
Attributes, (5) Career Development (with subsections including assessment, education and training, exploration, and employment history), (6) Career Aspirations, (7) Life Experiences, (8) Other Life Aspirations, (9) Challenges and Solutions, and (10) Goal-Setting/Planning. Following is a description of each of these components. When describing the person who is being profiled, we refer throughout the article to "the focus person." Also, for ease of reading, we have taken the liberty of alternating between gender specific pronouns.

\subsection{Community and champions}

Much has been written about the importance of people with disabilities and other life challenges becoming full members of their communities and establishing networks of support (Benson, Scales, \& Roehlkepartain, 2010; Crabtree \& Sherwin, 2011; Fullarton, 2006; Jim Casey Youth Opportunities Initiative, 2011; Kuehn, Pergamit, Macomber, \& Vericker, 2009; Larson \& Angus, 2010; Noonan et al., 2004; Rowe, Alverson, Unruh, Fowler, Kellems, \& Test, 2015). For many people with disabilities and other significant life barriers, their support systems tend to be overly represented by "paid supporters" and underrepresented by volunteer supporters and friends (Amado, 2013; Francis, Gross, Turnbull, \& Turnbull, 2015; Hochman, Carter, Bottema-Beutel, Harvey, \& Gustafson, 2015). This may primarily be due to society's tendency to shelter, protect, "take care of" and, intentionally or inadvertently, isolate people with disabilities. There are also long-held public misperceptions about disability. The challenge to those who advocate for and support people with disabilities, then, is to help individuals build their social networks to include others who will inspire them to be what author Carol Burbank calls "authentic and present in the world" (Burbank, 2015, p. 48). Others have used the term "authentic self" in this context (Ju, Roberts, \& Zhang, 2013).

Within the "community and champions" section of the LCAM, the focus person has an opportunity to identify her support team: family, friends, neighbors, employers, professionals and others who know this person well and have high regard and expectations for her (Berry \& Domene, 2015; Hennessey, Roessler, Cook, Unger, \& Rumrill, 2004; Larson, 2008; Lindstrom, Doren, \& Miesch, 2011; Simonsen \& Neubert, 2013; Tilson, 2015; Timmons, Hall, Bose, Wolfe, \& Winsor, 2011). People can rate the strength of their support team and identify others they 
would like to invite into the group. Since forming relationships is very much influenced by one's ability to communicate, the focus person can describe his preferred mode of communication and whether or not he uses alternatives/supplements to speech, including the use of augmentative devices, assistive technology, or sign language (Rowe et al., 2015). Individuals can identify their mentors or allies: those people with whom they can regularly touch base and count on for encouragement, guidance and the all-important push when needed (Powers, Schmidt, Sowers, \& McCracken, 2015; Silva, Bowers, \& Lerner, 2010). These would be people who have a true interest in this person's life successes. Berry and Domene (2015) call these supporters "relatable role models" (p. 86). This section also asks the focus person to take an inventory of her neighborhood to identify people and resources that are in reasonable proximity to her home, including transportation options, health care facilities, stores, community centers, businesses and so forth. For youth still in school, Rowe and her colleagues describe all of this as building "a network of people (e.g., family, friends, educators, and adult service providers) who provide services and resources in multiple environments to prepare students to obtain their annual transition and post-secondary goals aligned with their preferences, interests, and needs" (2015, p.123). Others describe this as helping people build "social capital" (Antle, Montgomery, \& Stapleford, 2009; Brown \& Lent, 2005; Hochman, Carter, Bottema-Beutel, Harvey, \& Gustafson, 2015; Racino, 2006; Rangarajan et al., 2009; Smith \& Zhang, 2009).

\subsection{Interests and aspirations}

In his seminal book, Zen and the Art of Making a Living, Laurence Boldt (1999) makes the case for building on interests and passions to discover one's career and life calling. What are the things that grab and hold your attention; things that energize you physically, mentally, emotionally, and/or spiritually? Interests are frequently expressed through hobbies, leisure-time pursuits, recreation, and avocations - as well as through occupations. You can tell when someone has a particular interest, because you observe them engaging enthusiastically in that activity, or intently focusing on an event or object. Interests are usually cultivated over time, and require that a person first be exposed to that activity or object of interest. For instance, a young child starts playing catch with her brother. Soon that activity intensifies. Every chance she gets, the girl plays ball. That early exposure leads to a lifetime passion for playing volleyball and other sports. Exposure precedes interest. Often people with life barriers have a narrow set of interests, or no expressed interests simply because there has never been a chance to get out in the world and see what exists. Many people have not explored the world of possibilities enough to have had an interest "sparked," and in many cases, people have cultivated unhealthy or socially unacceptable interests because these are the areas in which they have been primarily exposed (Jim Casey Youth Opportunities Initiative, 2012). People who have identified specific areas of interest are usually highly motivated to pursue them; interests are what fuel their actions. Our supporting role then is to encourage and guide them towards opportunities to dive into those interest areas. In this section of the LCAM there are 14 prompts to help the focus person identify those things that hold significance and meaning for them.

\subsection{Talents}

Everyone has certain abilities with which they seem to have been born; sometimes these are referred to as "natural gifts." These talents might be in the arena of athletics, music, art, creative writing, and other forms of expression. But they can also be represented by a warm smile, an ability to get along with others, an aptitude for taking things apart and putting them back together again, a knack for noticing small details, the ability to get around in a motorized chair and use an augmentative communication device, and so forth (Tilson, 2015).

Skills and knowledge, as with interests, are acquired over time through exposure, life experience, education, and training (Berry \& Domene, 2015; Bolles, 2010; Rowe et al., 2015). Talents include abilities in the areas of academics (e.g., language arts, mathematics, science), mechanics, daily living, creative arts, physical activity, communication (written, oral, and gestural), use of equipment, tools, technology and computers. In our field we often speak of life-, functional-, social-, employabilityand job search skills. There are also transferable skills, as demonstrated by the teenager who gets around town on a skateboard: she has coordination and agility, visual-spatial orientation, and problemsolving ability. Add to this the sense of adventure and fearlessness, and you have documented the very talents demanded in such occupations as firstresponders, law enforcement, armed services, and 
other careers that carry high physical risk. Strong job matches are contingent upon the fit between a person's talents and the demands of the job (Luecking, Fabian, \& Tilson, 2004). The LCAM has 12 prompts in this section, with designated space to identify the assessment tools or strategies that were used to identify the focus person's talents.

\subsection{Positive personal attributes}

This is a very broad category; in the LCAM it encompasses one's personality traits, temperament, idiosyncrasies, values, learning styles, degree of selfdetermination, and preferences. What are the things about a person's character that are recognized and genuinely appreciated by others? These might be sense of humor, ability to stay focused on a detailed task, willingness to learn new things, triumph over hardship, frankness, talent for listening to others, or sense of compassion. Part of getting to know someone is discovering the positive aspects of their personality, including their temperament, which is an individual's unique rhythm for responding to different environments, people, and events. Some people are unflappable; they seem to exude a sense of calm in even the most dire of circumstances. Compare them to others who are easily flustered at the merest suggestion of a problem situation. Some of us express our feelings openly; others of us prefer to keep our feelings private, and so forth. Human beings tend to prefer settings and experiences that match their temperament, which in turn energizes and motivates them (Armstrong, 2012). The opposite is also true: if they find themselves spending too much time in environments that are contrary to their natural temperaments, they are likely to feel drained, stressed out, and discouraged (Bolles, 2010). We are also motivated by our values, which may be thought of as our life philosophy; our unique perspective on what is important to attain in life and in our careers (Boldt, 1999; Orndorff, 2004). For example, someone may have a value that says having material wealth is of utmost importance; that person then may devote a significant amount of energy in this pursuit. Compare this with the person who values simplicity and tranquility. Other values include such things as having many friends, or living a solitary life; wanting to apply acquired skills and knowledge; wanting to help others; making the world safer, cleaner, healthier; fame and recognition - or quiet contribution; passing on skills and knowledge to others; being conventional - or being non-conformist. What we value in life is reflected in what we do, say, and think. It is closely related to our personality and temperament; and what Berry and Domene refer to as "positive personal beliefs." Our temperaments determine our ability to "reframe challenging [life] situations" (2015, p. 83).

Under positive personal attributes we also include one's degree of self-determination and autonomy. Self-determination has been covered substantially in the research literature, grant-funded projects, assessment instruments, and curricula (Calkins, Jackson, \& Beckmann, 2011; Cobb, Lehmann, NewmanGonchar, \& Alwell, 2009; Deci \& Ryan, 2007; Eisenman, Pell, Poudel, \& Pleet-Odle, 2015; Solberg, Howard, Gresham, \& Carter, 2012; Ward, 2005; Wehmeyer et al., 2007). It has been defined in myriad ways. Recently Rowe and her colleagues summarized self-determination: "the ability to make choices, solve problems, set goals, evaluate options, take initiative to reach one's goals, and accept consequences of one's actions." (2015, p. 116). Others emphasize the importance of the individual presenting his strengths, talents, and desires to others, in order to positively influence the perceptions others hold of him (Ju, et al., 2013); and learning to articulate/present their goals and needs (ProvenmireKirk et al., 2015; Ryan \& Deci, 2000). Martin, Hennessey, McConnell, and Kazimi (2011) view selfdetermination as a concept built upon 8 constructs: knowledge of strengths and limitations, disability awareness, employment, goal setting and attainment, persistence, proactive involvement, self-advocacy, and utilization of supports. Motivation, drive and tenacity are considered key to achieving one's life goals (Berry \& Domene, 2015; Boldt, 1999; Burbank, 2015; Goldberg, Higgins, Raskind, \& Herman, 2003; Tilson, 2015). We must also be mindful that many people with disabilities need us to help them find their voices in expressing the very things that they want in their lives; for without such support they can often be directed towards options for living and working that are far from ideal (Migliore, Mank, Grossi, \& Rogan, 2007). Self-determination can be enhanced by providing people opportunities to take reasonable risks, try things out, and discover talents and attributes they and others may not have realized they had.

In the LCAM, the focus person can identify her dominant learning style(s), sometimes called "multiple intelligence" - the manner in which an individual naturally prefers receiving, processing and expressing information. Psychologist and researcher Howard Gardner and others have identified the following learning styles: bodily kinesthetic, 
musical, visual-spatial, intrapersonal, interpersonal, verbal-linguistic, mathematical-logical, and naturalist (Armstrong, 2012; Freeman \& Walsh, 2013; Gardner, 1999). The notion of learning style has significant implications for how we acquire and use skills, perform tasks, relate to others, and approach learning in general. It certainly has tremendous impact on our life and career development.

All of these pieces of information fill in a complete and compelling picture of the focus person. In the LCAM we also include space to identify those things that worry or concern the person, as well as his expressed "dislikes" - things in which he has no interest, or would prefer to avoid if possible, or things, people and/or settings that make him uncomfortable for whatever reason. It is incumbent upon us, as allies, to know what people dislike as well as those things that bring them satisfaction. Related to career development we should be asking "What is a job, or a job setting, or type of work task that you know you do NOT want to do?" If someone has had previous work experience and tells you they did not like the job, we should probe further: "What was it about the job you didn't like?" Too often people are encouraged to take jobs that really go against their core dislikes - and this is usually a recipe for failure, when it comes to job performance and retention (Luecking, Fabian, \& Tilson, 2004). One last thought: everyone has quirks and idiosyncrasies that, for better or worse, are considered part of our personality. Most of us can find success in life in spite of - or even because of - these characteristics. Unfortunately, people with disabilities are often denied various life experiences, or live under tightly controlled circumstances or have behavior interventions, because they exhibit quirky rather than truly problematic behaviors. Again, those of us who advocate for the full community inclusion of people with disabilities need to be able to make that distinction.

\subsection{Career development}

The next major section in the LCAM focuses on career development and includes subsections related to assessment, education and training, exploration, and employment history, which are critical components of best-practice transition programs as described by (Brewer et al., 2011), and championed by the Division on Career Development and Transition (DCDT) of the Council for Exceptional Children and the Association of People Supporting EmploymentFirst (APSE). The Delaware Department of
Education and its partners envision that all educational activities and programs fall under the rubric of career development, with transition components intended to ensure the access of students with disabilities to those opportunities afforded their non-disabled peers. (Fig. 2, Delaware Transition Logic Model). Elements of this model reflect the work of Mazzotti, Rowe, Cameto, Test, and Morningstar (2013), Grigal, Hart, and Migliore, (2011), Kohler and Field (2003), and many others.

The American Heritage Dictionary (2011) defines "career" as a path or progress through life or history; and a profession or occupation chosen as one's life's work. According to the U.S. Department of Labor, there are 20,000 unique occupations categorized by 16 career clusters (O-Net, 2015). While this presents a world of possibility, it can also be a daunting process for human beings to determine their career path. Career development is an ongoing, iterative process (Boldt, 1999; Kalchik \& Oertle, 2010; Tilson, 2015). As depicted in Fig. 3, phases include selfawareness, awareness of opportunities, exploration and preparation, all of which Rowe and her colleagues describe as "learning about opportunities, education, and skills needed in various occupational pathways to choose a career that matches one's strengths and interests" (2015, p. 118). It also includes one's employment history; with each experience leading to further self-awareness, and new ventures. This requires intention, attention and effort; "it takes 'outer work' like research, learning, outreach, and followthrough, and it takes 'inner work' like soul-searching, thought, and decision-making" (Boldt, 1999, p. xiv). In other words, careers do not just happen; they evolve and revolve over time.

The LCAM has sections where career and transition assessment information can be summarized and documented; it asks the individual to identify where they are on the career development continuum: awareness, exploration, preparation; active job search; or job maintenance/career advancement. It prompts the focus person to consider what further education and training he might need in order to pursue his career goals. As reflected in the logic model in Fig. 2, our education and training are inextricably bound to our career trajectories; therefore the LCAM has several sections highlighting the person's formal and informal educational experiences, including career and technical courses and workbased learning, which is one of the 16 predictors identified by Test et al. (2009), and further addressed by Berry and Domene (2015), Carter et al. (2010), 


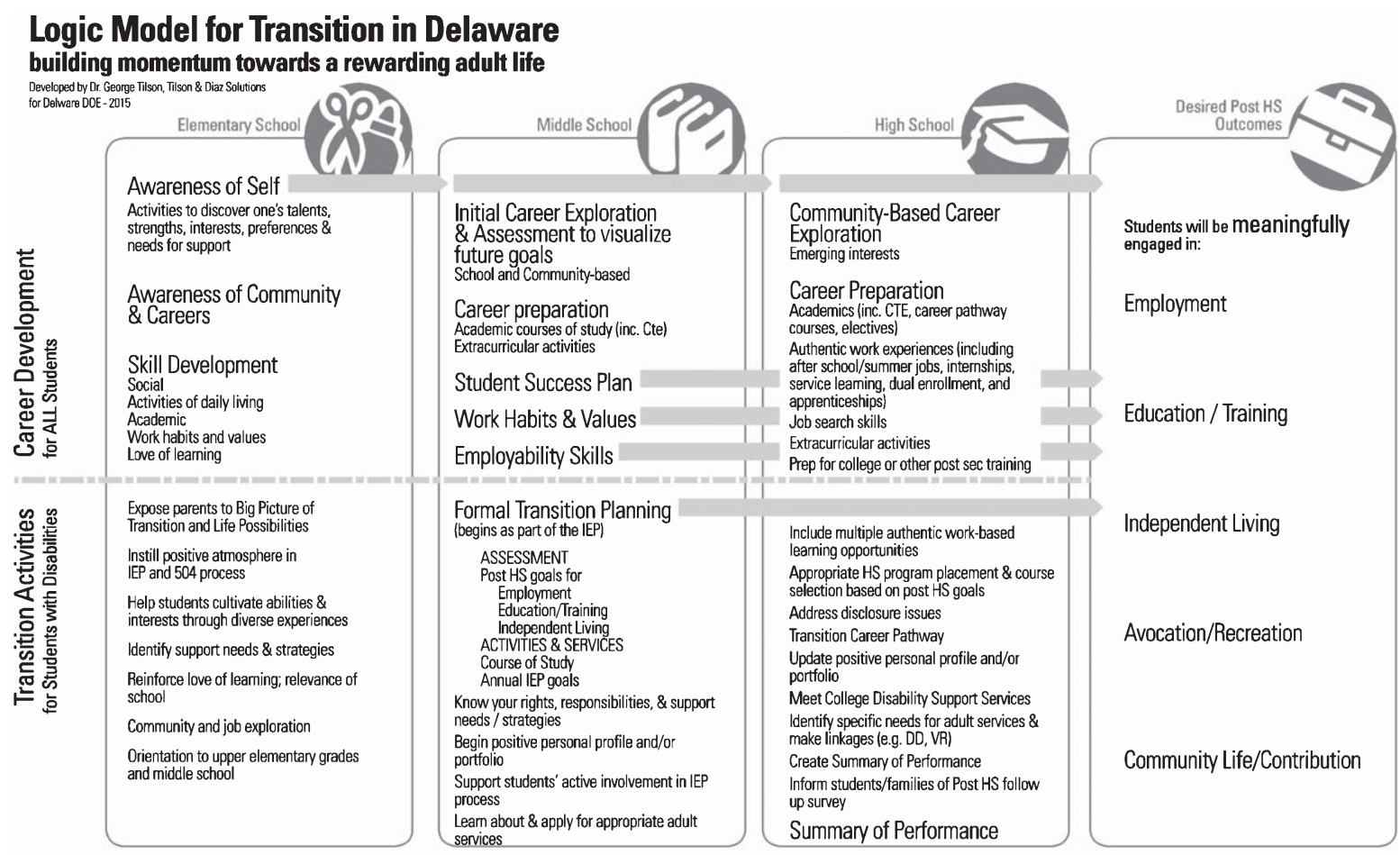

RUNNING THEMES: Self-Determination; Person-Centered Approach; High Expectations; Champions/Supporters; Cross-Agency Collaboration and Contribution (programs, funding, \& data sharing)

Fig. 2. Logic Model for Transition in Delaware.

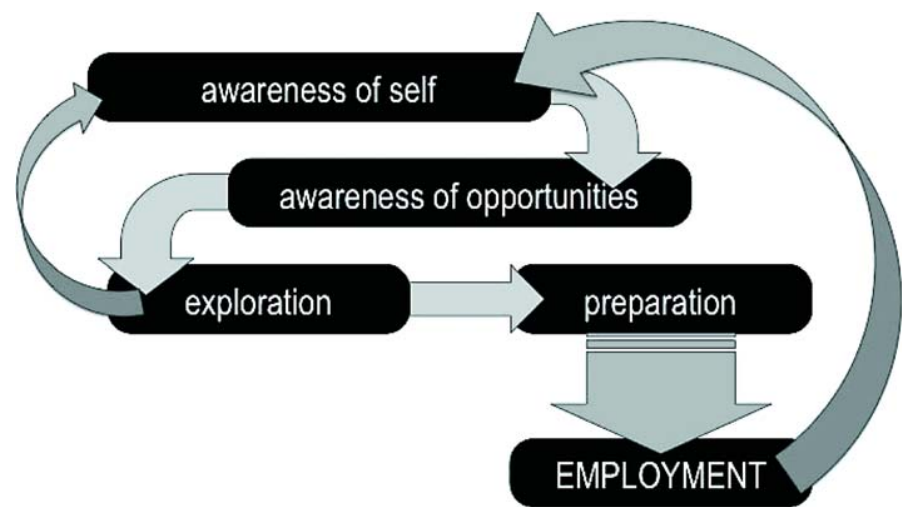

Fig. 3. Components of Career Development.

Luecking and Tilson (2009), and Rowe et al. (2015). The LCAM also captures the extent to which the individual has participated in and completed general education courses, and received technical/trade certifications. U.S. Department of Education (2007) estimated that "among adults over the age of 16 who did not have a high school diploma or equivalent in 2005 , only $1 \%$ participated in degree or diploma programs at the post secondary level and only $4 \%$ participated in work-related courses. These findings suggest that a critical component of any employment intervention will be procedures to reliably engage individuals and to establish targeted skills. Future research will have to determine if adult education that effectively retains participants in training and establishes academic and job skills can improve employment outcomes." (p. 72). This was further substantiated by Honeycutt et al. 2015, who found that youth with disabilities often do not receive the same intensity of educational preparation as their peers 
without disabilities. This is highly problematic, as is the finding that many youth with disabilities do not disclose their need for accommodations when attending post secondary institutions - or on their jobs (The 2020 Federal Youth Transition Plan, 2015; Boutin \& Wilson, 2009; Gregg, 2007; Madaus, 2008; Newman et al., 2011; Riconscente, 2004). In creating a portfolio or an instrument such as the LCAM, youth and adults have at their fingertips a record of critical information for making decisions about next steps towards their goals in education, training, and employment and for requesting and receiving appropriate supports for success.

The next two subsections in the LCAM are devoted to career exploratory activities and employment history. Rowe and her colleagues describe work experience as "any activity that places the student in an authentic workplace and could include work sampling, job shadowing, internships, apprenticeships, and paid employment. Paid employment can include existing standard jobs in a company or organization or customized work assignments negotiated with the employer, but these activities always feature competitive pay paid directly to the student by the employer." (2015, p. 118). This is one of the most overlooked areas in getting to know students and job seekers, particularly those individuals who may have had very limited, or no, previous work experiences. Employers want to know that a candidate has distinct skills to accomplish specific company goals. How the individual job seeker acquired certain skills may be less important than the fact that he or she has them - and can demonstrate them. People acquire skills in many ways: primarily through formal education and training; previous volunteer or paid jobs, and community service. However, we must also recognize the skill acquisition that comes from informal life experiences (for example, a neighbor who teaches a teenager to repair a car engine; a young adult showing a senior citizen how to use the internet); and self-training (the inmate who studies for the law school entrance examination; the young man with quadriplegia who teaches himself to cook using adaptive equipment; the youngster who learns how to play tennis by watching it on television). In the LCAM, individuals can describe those experiences and then reflect on them: what they thought they did well; what they struggled with; the feedback they received from supervisors, teachers and others; what they might have done differently; and what they learned about themselves in the process. Reflection on one's life experiences the good, the bad, and the ugly - are important for all of us, and we should be sure to encourage those we support to mull over what they learned, and how those experiences affected them. After all, these experiences can have a powerful impact on self-esteem, independence and quality of life (Boeltzig, Timmons, \& Butterworth, 2008; McDonnall, 2010).

\subsection{Career aspirations}

In the original positive personal profile, we began by asking people to identify their career dreams and aspirations. What we have discovered is that some people know very clearly what it is they want to do career-wise; however, more often than not, people are at a loss to answer questions of themselves such as: What do I really want out of life? Who am I? Who can I be? How do I picture my life in the future? Where and with whom would I like to be living? What would I like to be doing for fun? For work? What would I like to accomplish? What activities would be fulfilling to me? When it comes to dreams and goals, the sky's the limit; however, many of us are reluctant to express these to anyone, lest they criticize our aspirations, or accuse us of being unrealistic (Burbank, 2015). Unfortunately, many people, especially individuals with disabilities and other life barriers, are discouraged from identifying and talking about their life dreams and goals, out of concern that they will be disappointed if they fall short of their goals (Tilson, 2015). Yet dreams and goals are what propel us to take action in our lives (Bolles, 2010). In the LCAM we purposely put career aspirations later in the instrument, having found that, for most people, it is easier to answer the questions about one's career aspirations after reflecting on the other attributes and experiences.

The process of life's work planning can be defined, in a general sense, as creating a picture of the world you want to live in and then organizing your energies into building it. It takes being part dreamer, part builder. If we are not dreamers, our aspirations will be too low, and we will sink into emptiness, leaving nothing of lasting value to those who follow. Yet, if we are not builders, if our dreams are not given the shape, form, and substance of living reality, then they are nothing more than phantoms and platitudes." (Boldt, 1999, p. xxvi)

In the LCAM, we provide the following prompt: "Based on what I have learned about myself so far, my top three career areas are...." This reinforces 
the mindset that career development is an iterative process.

\subsection{Life experiences}

In line with our philosophy that careers encompass the full range of human experiences, we added $2 \mathrm{sec}-$ tions in the LCAM: life experiences and other life aspirations. Most of us acknowledge that in our own lives events and experiences, positive and negative, have shaped us personally and professionally. Being part of our community shapes us. For transition-age youth, Rowe and her colleagues (2015) talk about how these "outside of school" experiences interface with, and enhance, what students are learning in their classrooms. We would take it a step further and say that diverse life experiences are educational in and of themselves. Further skill acquisition occurs through hands-on experiences. Consider all of the skills we attain and develop through trial and error (entertaining young children; building a model airplane; sorting laundry; cleaning up a campsite; learning how to use a computerized speaking device; rescuing an animal; raising children; composing music; organizing parties; surfing the internet; manipulating a motorized wheelchair; and so forth). Some of us are fortunate to have learned many skills through on-thejob experiences. Does this mean that those without such experiences cannot acquire skills? No. This is where other life experiences come into play. Often it is through our hobbies and recreational activities that we acquire specific skills (Bolles, 2010).

When getting to know our students and job seekers, we must try to ascertain what they - and people in their circle of support - have accomplished in their lives. What are they proud of? Have they received any special recognitions or awards? Even people with the most significant disabilities have achieved specific milestones in their lives that deserve recognition. The degree of complexity of those achievements varies from person to person; what matters most is that, for the individual, it represents a life accomplishment. And this bit of information can prove invaluable as we assist people in finding meaningful livelihoods.

\subsection{Other life aspirations}

Again, if a meaningful life is a balanced life, it is important to acknowledge that human beings desire to accomplish other things in addition to work. In the spirit of an expanded view of "career," the LCAM has a section where the focus person can express those other aspirations, and identify who might help them pursue these. We have also found that this section is particularly useful for those individuals who, for whatever reason, do not have competitive employment on their life's radar. This does not mean they cannot be participating and contributing members of our communities, to the greatest extent imaginable.

\subsection{Challenges and solutions}

The word "challenge" may be synonymous with the words barrier, limitation, deficit, weakness, idiosyncrasy, pet peeve, shortcoming, road block, hindrance, problem, barricade, difficulty, or obstacle - but it can also refer to risk and adventure. In fact, life may be thought of as a series of opportunities and challenges. We can be born with certain challenges (for example, with a physical or cognitive disability, a medical condition, a propensity for behaviors that go against the norm, or anomalies in physical appearance), or into challenging life circumstances (such as poverty, membership in an ostracized religious, ethnic group, or other demographic group). And certainly, we will encounter numerous and diverse unexpected challenges as we progress through life. Some of us are better equipped, or have adequate support systems, that allow us to handle these challenges; others of us seem to collapse under the pressure of the challenges with which we are confronted (Tilson, 2015).

Sometimes people face challenges because of opportunities they have never had, such as when people cannot read because they have never been taught how to read; or individuals who can not articulate the kinds of jobs they would like because they have had little exposure to the work world. Some people run into a lifetime of challenges because of poor choices they have made. People with disabilities face a unique situation: often their disabilities are considered their primary challenges, when in fact, each person is affected by his/her disability in different ways. The disability itself is not the challenge, rather it is the specific dilemmas posed by the disability. Having a learning disability is not a specific challenge, but not being able to comprehend verbal instructions is. Having a brain injury is not a specific barrier; however, having unintelligible speech is a definite challenge. Not having access to public transportation might be the specific barrier for one blind person; while her counterpart has access to transportation but is not permitted by her family to use the bus, out of fear for her safety. The challenge of an intellectual disability may 
be, for one person, the inability to write a coherent sentence - for another it might be difficulty in picking up social cues and building friendships (Francis, Gross, Turnbull, \& Parent-Johnson, 2013; Hutchinson, Versnel, Chin, \& Monby, 2008; Nadeau, 2005; Wehman, 2012.)

In this section of the LCAM, the focus person and her supporters are asked to list the specific challenges she faces in any or all of 10 areas: Career/ Employment; Residence and Daily Living; Further Education/Training; Health, Well-Being and Personal Care; Community Participation/Membership/ Contribution; Leisure Pursuits/Avocations; Relationships/Social Interactions; Transportation; Financial and Legal (including managing benefits); Physical Safety and Security; areas identified by many authors including Achterberg, Wind, and FringsDresen (2012), and Rowe et al. (2015).

For each challenge, the focus person and his team of advocates, are called upon to identify potential solutions or accommodations. These are strategies that might alleviate or lessen the impact of the challenge; they might fall under the category of physical strategies (e.g., equipment, facilities, assistive technology), special services (e.g., job coaches, sign language interpreters; personal care assistants); or creative problem-solving (e.g., flexible schedules, use of phone apps to remind someone of task sequences). These are strategies that help people feel competent, confident, and comfortable - and highlight their assets rather than deficits (Tilson, 2015). These solutions may be "high tech, low tech, or no tech" and incorporate methodology useful to many people, not just those with disabilities; a concept commonly referred to as universal design, for living and learning (Burgstahler \& Moore, 2009; Unger $\&$ Kregel, 2003). When implementing any support strategy, it helps to identify a point person: someone who can ensure that the strategy is indeed being implemented - and who can help find alternative approaches when a strategy is not effective. In all cases, the focus person should be as involved as possible in coming up with, putting into place, and evaluating solutions. This is in and of itself a major aspect of self-determination (McConnell et al., 2013).

\subsection{Goal-setting/planning}

To paraphrase a common expression, if you don't know where you're going, no telling where you'll end up. Gathering all of this "discovery" information is only as useful as the extent to which many ideas are generated - for taking action. In turn, action requires goal-setting (Holland, 1997; McConnell et al., 2013; Tilson, 2015). Life coach and counselor Nancy Schlossberg (1994) frames it this way: effective planning requires that people "take stock of" their situations, themselves, their supports and their strategies. The author and his colleagues have found with the positive personal profile, and now the LCAM, that as we unlock, uncover and acknowledge all of the attributes, experiences, and aspirations of the individuals we support, the more creative brainstorming seems to occur. A current buzzword is "crowd-sourcing" - and it seems apropos of this process. Resourceful and innovative solutions arise when a person's network expands and multiple contacts are tapped for ideas and "what ifs." Goal-setting is then the act of formalizing these ideas; turning them into measurable action steps. The authors are partial to the SMARTER approach: making goals and objectives Specific, Measurable, Action-Oriented, Reachable, Time-bound, Evaluate-able, and Revise-able. And we believe that for every SMARTER goal or objective, there must be people willing to directly assist in the implementation - and some brave soul who will step up to ensure that activities have in fact taken place, determine "if not, why not", and then go back to the drawing board with all the players, to determine how these activities can be modified or even replaced with other actions. Often, it may be that entirely new goals and objectives need to be established. This is particularly relevant in the case of developing meaningful post secondary goals for transitioning youth, and IPE and ISP goals for adults with disabilities.

\section{Conclusion}

Whether the end result is a formal document such as the IEP, IPE, ISP, or a resume, college essay, worksheet to prepare for a person-centered meeting, or job interview, we hope the LCAM (or any derivatives invented by creative stakeholders) will be a useful mechanism for highlighting and celebrating the positive attributes and desires of each focus person. In this day and age where technology changes in an instant, and a billion waves of information bombard us at any given moment, it is not surprising to feel that past, present and future are inextricably intertwined - or hyperlinked. The up side is that our interconnectedness should allow for more shared knowledge, resources and better outcomes. The downside is that it can also lead people to feel overwhelmed. 
Certainly in our fields of education and human services, professionals and other stakeholders are feeling increasingly frantic and stressed, to the point that even the most energetic and enthused among us cringe at new initiatives, laws, policies, procedures, technical assistance, and expectations. Even the most well-intended of these can seem to the recipients like the item of food that finally fell off the proverbial overly-crowed plate. Pham (2013) speaks of the need in our field for more efficient tools, streamlined processes, and more relevant, timely and accessible professional development options to help lessen this stress. Numerous authors have drawn attention to the importance of field work, mentoring and coaching of professionals (Provenmire-Kirk et al., 2015; Rock et al., 2009; Shriner, Schlee, Hamil, \& Libler, 2009). Tilson \& Simonsen (2013) identified 4 attributes of highly effective employment specialists working with transition-age youth: principled optimism; cultural competence; business-oriented professionalism; and networking savvy. These are competencies beyond the mere mechanics of our work; they are the underlying human traits that fuel the mechanics. The LCAM is intended, like so many other resources, to be "person-centered." By the same token, how "personcentered" are we towards the very professionals who are closest to our customers? After all, these are the professionals who are doing astounding things so that every person with a disability can realize "a larger, more expansive [life] story." (Burbank, 2015, p.11).

\section{Acknowledgments}

Sandra J. Miller is co-developer of the LCAM and as the transition specialist with the Delaware Division of Vocational Rehabilitation has lent an invaluable perspective. The author is ever grateful to her and would also like to thank Dale Matusevich, Delaware Department of Education and Marissa Catalon, Delaware Division of Developmental Disabilities Services, who have been instrumental in championing and piloting the tool in Delaware. Further appreciation is extended to APSE for the opportunity to present the LCAM at the 2015 annual conference in Philadelphia and The Journal of Vocational Rehabilitation for inviting the author to submit to this special issue. The author also thanks Jose Luis Diaz and Valencia Harper for their editorial assistance. Finally, kudos and sincerest thanks to the stakeholders with whom I have had the privilege to work and learn over these years.

\section{Special note}

The developers of the LCAM intend for it to be available to the public as a fair use resource as defined by Creative Commons http://creativecommons.org

It is available online at www.TilsonDiaz Solutions.com. We encourage the readers to try it out, modify it, improve it. Our only request is that we receive your feedback, pro and con; in the following manner: "adapted with permission from George Tilson, Tilson \& Diaz Solutions, Inc, and Sandra J. Miller, Delaware Division of Vocational Rehabilitation." Readers may contact the author at George@TilsonDiazSolutions.com.

\section{Conflict of interest}

None to declare.

\section{References}

Achterberg, T., Wind, H., \& Frings-Dresen, M. (2012). What are the most important factors for work participation in the young disabled? An expert view. Disability and Rehabilitation, 34(18), 1519-1525.

Alliance for Excellent Education, America's Promise, Johns Hopkins University, 2015]

Amado, A. (2013). Friends: Connecting people with disabilities and community members. Minneapolis, MN: University of Minnesota, Institute on Community Integration, Research and Training Center on Community Living.

Antosh, A., Sherlock, P., Blair, M., Edwards, K., Goode, T., Hewitt, A., Izzo, M., Johnson, D., Raynor, O., Riddle, I., Shanley, J., Walker, R., \& Wehmeyer, M. (2013). A collaborative interagency, interdisciplinary approach to transition from adolescence to adulthood. Silver Spring, MD: Association of University Centers on Disabilities.

American Heritage ${ }^{\circledR}$ Dictionary of the English Language (5th ed.). (2011)

Antle, B., Montgomery, G., \& Stapleford, C. (2009). The many layers of social support: Capturing the voices of young people with spina bifida and their parents. Health and Social Work, 34(2), 97-106.

Armstrong, T. (2012). First, discover their strengths. Educational Leadership, 70(2), 10-16.

Benson, P., Scales, P., \& Roehlkepartain, E. (2010). A fragile foundation: The state of developmental assets among American youth (2nd Edition). Minneapolis, MN: Search Institute.

Berry, S., \& Domene, J. (2015). Supporting postsecondary students with sensory or mobility impairments in reaching their career aspirations. Career Development and Transition for Exceptional Individuals, 38, 78-88.

Boeltzig, H., Timmons, J. C., \& Butterworth, J. (2008). Entering work: Employment outcomes of people with developmental disabilities. International Journal of Rehabilitation Research, 31(3), 217-223. 
Boldt, L. (1999). Zen and the art of making a living: A practical guide to creative career design. Penguin.

Bolles, R. (2010). What color is your parachute? 2010: A practical manual for job-hunters and career-changers. Berkeley.

Boutin, D., \& Wilson, K. (2009). An analysis of vocational rehabilitation services for consumers with hearing impairments who received college or university training. Rehabilitation Counseling Bulletin, 52, 156-166.

Brewer, D., Karpur, A., Pi, S., Erickson, W., Unger, D., \& Malzer, V. (2011). Evaluation of a multi-site transition to adulthood program from youth with disabilities. Journal of Rehabilitation, 77(3), 3.

Brown, S., \& Lent, R. (2005). Career development and counseling: Putting theory and researchto work. John Wiley.

Burbank, C. (2015). Answering the call to adventure: Love the story of your life. Accokeek, MD: Storyweaving Press.

Burgstahler, S., \& Moore, E. (2009), Making student services welcoming and accessible through accommodations and universal design. Journal of Postsecondary Education and Disability, $21(3), 155-174$.

Calkins, C., Jackson, L., \& Beckmann, C. (2011). National Gateway to Self-Determination. Research to practice in selfdetermination. Self-Determination and Self-Advocacy, Issue 1.National Training Initiative on Self-Determination and the Association of University Centers on Disabilities

Carter, E., Austin, D., \& Trainor, A. (2012). Predictors of postschool employment outcomes for young adults with severe disabilities. Journal of Disability Policy Studies, 23(1), 50-63.

Carter, E., Dutchman, N., Ye, S., Trainor, A., Swedeen, B., \& Owens, L. (2010). Summer employment and community experiences of transition-age youth with severe disabilities. Exceptional Children, 76, 194-212.

Cobb, B., Lehmann, J., Newman-Gonchar, R., \& Alwell, M. (2009). Self-determination for students with disabilities: A narrative metasynthesis. Career Development for Exceptional Individuals, 32, 10-114.

Crabtree, L., \& Sherwin, A. (2011). Begin with the end in mind: Promoting mental health, social participation, and selfdetermination in the transition from school to adult life. In S. Bazyk (Ed.), Occupational therapy's role in promoting mental health and social participation in children and youth. Bethesda, MD: AOTA Press, pp. 263-279.

Deci, E., \& Ryan, R. (2007). Facilitating optimal motivation and psychological well-being across life's domains. Canadian Psychologist, 49, 14-23.

Dresser, K., Zucker, P., Orlando, R., Krynski, A., White, G., Karpur, A., Deschenes, N., \& Unruh, D. (2009). Collaborative approach to quality improvement in process, progress, and outcomes: Sustaining a responsive and effective transition system. Transition of youth and young adults with emotional or behavioral difficulties: An evidence-supported handbook. Baltimore: Brookes Publishing, pp. 291-321.

Eisenman, L., Pell, M., Poudel, B., \& Pleet-Odle, A. (2015). "I think I'm reaching my potential": Students' self-determination experiences in an inclusive high school. Career Development and Transition for Exceptional Individuals, 38, 101-112.

Francis, G., Gross, J., Turnbull, A., \& Turnbull, H. (2015). An exploratory investigation into family perspectives after the Family Employment Awareness Training. Career Development and Transition for Exceptional Individuals, 38, 68-77.
Francis, G., Gross, J., Turnbull, R., \& Parent-Johnson, W. (2013). Evaluating the effectiveness of the family employment awareness training in Kansas: A pilot study. Research and Practice for Persons with Severe Disabilities, 38, 1-14.

Freeman, G., \& Wash, P. (2013). You can lead students to the classroom, and you can make them think: Ten brain-based strategies for college teaching and learning success. Journal on Excellence in College Teaching, 24, 99-120.

Fullarton, S. (2006). A case study of school experiences for successful young adults with learning disabilities. (Doctoral dissertation). Retrieved from ProQuest Digital Dissertations. (AAT MR25773)

Gardner, H. (1999). Intelligence reframed: Multiple intelligences for the 21st century. Basic Books, New York.

Goldberg, R., Higgins, E., Raskind, M., \& Herman, K. (2003). Predictors of success in individuals with learning disabilities: A qualitative analysis of a 20-year longitudinal study. Learning Disabilities Research and Practice, 18, 222-236.

Gonzalez, R., Rosenthal, D., \& Kim, J. (2011). Predicting vocational rehabilitation outcomes of young adults with specific learning disabilities: Transitioning from school to work. Journal of Vocational Rehabilitation, 34, 163-172.

Gregg, N. (2007). Undeserved and unprepared: Postsecondary learning disabilities. Learning Disabilities Research \& Practice, 22(4), 219-228.

Hemmeter, J., Donovan, M., Cobb, J., \& Asbury, T. (2015). Long term earnings and disability program participation outcomes of the Bridges transition program. Journal of Vocational Rehabilitation, 42, 1-15.

Hennessey, M., Roessler, R., Cook, B., Unger, D., \& Rumrill, P. (2004). Employment and career development concerns of postsecondary students with disabilities: Service and policy implications. Journal of Postsecondary Education and Disability, 19, 39-55.

Hochman, J., Carter, E., Bottema-Beutel, K., Harvey, M., \& Gustafson, J. (2015). Efficacy of peer networks to increase social connections among high school students with and without autism spectrum disorder. Exceptional Children, 82, 96-116.

Holland, J. L. (1997). Making vocational choices: A theory of careers. 3rd Edition. EnglewoodCliffs, NJ: Prentice-Hall.

Honeycutt, T., Thompkins, A., Bardos, M., \& Stern, S. (2015). State differences in the vocational rehabilitation experiences of transition-age youth with disabilities. Journal of Vocational Rehabilitation, 42, 17-30.

Horvath-Rose, A., Stapleton, D., \& O'Day, B. (2004). Trends in outcomes for young people with work disabilities: Are we making progress? Journal of Vocational Rehabilitation, 21, 175-187.

Hutchinson, N., Versnel, J., Chin, P., \& Munby, H. (2008). Negotiating accommodations so that work-based education facilitates career development for youth with disabilities. Work: A Journal of Prevention, Assessment \& Rehabilitation, 30, 123-136.

Jim Casey Youth Opportunities Initiative (2012). Issue Brief \#6: Case planning for healthy development. St. Louis, MO: JCYOI.

Ju, S., Roberts, E., \& Zhang, D. (2013). Employer attitudes towards workers with disabilities: A review of research in the past decade. Journal of Vocational Rehabilitation, 38, 113-123.

Jun, P. (2015). The Career Compass: 10 Essential Ideas for Navigating the New Career Landscape. Retrieved from http:// 99u.com/articles/43499/the-career-compass-10-essential-idea s-for-navigating-the-new-career-landscapeutm_cource $=99$ U \& 
utm_campaign=79d681f71b-Weekly_05_10_2015\&utm_med ium=email\&utm_term=0_bdafaef00-79d681f71b-145346101

Kalchik, S., \& Oertle, K. (2010). The Integral role of Career Development in Supporting Programs of Study and Career Pathways. Transition Highlights. Issue I. Office of Community College Research and Leadership.

Kosine, N., Steger, M., \& Duncan, S. (2008). Purpose-centered career development: A strengths-based approach to finding meaning and purpose in careers. Professional School Counseling, 12(2), 133-136.

Kuehn, D., Pergamit, M., Macomber, J., \& Vericker, T. (2009). Vulnerable youth and thetransition to adulthood: Multiple pathways connecting to school and work. Washington, D.C.: Office of the Assistant Secretary for Planning and Evaluation, Office of Human Services Policy, the U.S. Department of Health and Human Services.

Landmark, L., Ju, S., \& Zhang, D. (2010). Substantiated best practices in transition: Fifteen plus years later. Career Development for Exceptional Individuals, 33, 165-176.

Larson, A. (2008). The development of work self-efficacy in people with disabilities (Doctoral dissertation). Retrieved from ProQuest Digital Dissertations (AAT 3310764).

Larson, R., \& Angus, R. (2010). 4 Pursuing Paradox: The Role of Adults in Creating Empowering Settings for Youth. In Empowering settings and voices for social change, 277-294.

Lindstrom, L., Doren, B., \& Miesch, J. (2011). Waging a living: Career development and long-term employment outcomes for young adults with disabilities. Exceptional Children, 77(4), 423-434.

Luecking, R., Fabian, E., \& Tilson, G. (2004). Working Relationships: Creating Career Opportunities for Job Seekers with Disabilities Through Employer Partnerships. Brookes Publishing Company.

Luecking, R., \& Tilson, G. (2009). Planning for work experiences. In R.G. Luecking, The Way to Work: How to Facilitate Work Experiences for Youth in Transition. Brookes Publishing Company, pp. 41-64.

Madaus, J. W. (2008). Employment self-disclosure rates and rationales of university graduates with learning disabilities. Journal of Learning Disabilities, 41(4), 291-299.

Martin, J., Hennessey, M., McConnell, A., \& Kazimi, N. (2011). The transition success assessment development study: Phases $I$ \& II. [PowerPoint slides], Retrieved at the 16th International DCDT Conference, Kansas City, MO.

McConnell, A., Martin, J., Juan, C., Hennessey, M., Terry, R., el-Kazimi, N., \& Willis, D. (2013). Identifying nonacademic behaviors associated with post-school employment and education. Career Development and Transition for Exceptional Individuals, 36, 174-187.

McDonnall, M. (2010). Factors predicting post-high school employment for young adults with visual impairments. Rehabilitation Counseling Bulletin, 54, 36-45.

Migliore, A., Mank, D., Grossi, T., \& Rogan, P. (2007). Integrated employment or sheltered workshops: Preferences of adults with intellectual disabilities, their families and staff. Journal of Vocational Rehabilitation, 26, 5-19.

Nadeau K. G. (2005). Career choices and workplace challenges for individuals with ADHD. Journal of Clinical Psychology, 61(5), 549-563,

Newman, L., Wagner, M., Knoke, A., Marder, C., Nagle, K., Shaver, D., \& Schwarting, M. (2011). The post-high school out- comes of young adults with disabilities up to eight years after high school. Retrieved from the National Longitudinal Transition Study-2 (NLTS2) (NCSER 2011-2005). Menlo Park, CA: SRI International.

Noonan, B., Gallor, S., Hensler-McGinnis, N., Fassinger, R., Wang, S., \& Goodman, J. (2004). Challenge and success: A qualitative study of the career development of highly achieving women with physical and sensory disabilities. Journal of Counseling Psychology, 51, 68-80.

Noonan, P., Morningstar, M., \& Erickson, A. (2008). Improving interagency collaboration. Effective strategies used by high-performing local districts and communities. Career Development for Exceptional Individuals, 31, 132-143.

Noonan, P., McCall, Z., Zheng, C., \& Gaumer Erickson, A. (2012). An analysis of collaboration in a state-level interagency transition team. Career Development for Exceptional Individuals, 35, 143-154

Oertle, K., Plotner, A., \& Trach, J. (2013). Rehabilitation professionals' expectations for transition and interagency collaboration. Journal of Rehabilitation, 79, 25-35.

O-Net. Retrieved from Department of Labor Online Web site: https://www.onetonline.org

Orndorff, R. (2004). Becoming the best me: 10 career and character education essentials. Indianapolis: JIST Publishing, Inc.

Pham, Y. (2013). An exploratory survey of transition teaching practices: Results from a national sample. Career Development and Transition for Exceptional Individuals, 36, 163-173.

Powers, L., Schmidt, J., Sowers, J., \& McCracken, K. (2015). Qualitative investigation of the influence of STEM mentors on youth with disabilities. Career Development and Transition for Exceptional Individuals, 38, 25-38.

Provenmire-Kirk, T., Diegelmann, K., Crump, K., Schnorr, C., Test, D., Flowers, C., \& Aspel, N. (2015). Implementing CIRCLES: A new model for interagency collaboration in transition planning. Journal of Vocational Rehabilitation, 42, 51-65.

Racino, J. (2006). Social support. In G. Albrecht (Ed.), Encyclopedia of disability. Thousand Oaks, CA: SAGE, pp. 1469-1470.

Rangarajan, A., Fraker, T., Honeycutt, T., Mamun, A., Martinez, J., O'Day, B., \& Wittenburg, D. (2009). The Social Security Administration's Youth Transition Demonstration projects: Washington, DC: Mathematica Policy Research.

Riconscente, S. (2004). College career development centers: Serving students with learning disabilities (Doctoral dissertation). Retrieved from ProQuest Digital Dissertations (AAT3124563).

Rock, M. L., Gregg, M., Howard, P. W., Ploessl, D. M., Maughn, S., Gable, R. A., \& Zigmond, N. P. (2009). See me, hear me, coach me. Journal of Staff Development, 30(3), 24-26, 28-31.

Rowe, D., Alverson, C., Unruh, D., Fowler, C., Kellems, R., \& Test, D. (2015). A Delphi study to operationalize evidencebased predictors in secondary education. Career Development and Transition for Exceptional Individuals, 38, 113-126.

Ryan, R., \& Deci, E. (2000). Self-determination theory and the facilitation of intrinsic motivation, social development, and well-being. American Psychologist, 55, 68-78.

Schlossberg, N. (1994). Overwhelmed: Coping with life's ups and downs. NY: Lexington Books.

Shogren, K., \& Turnbull, A. (2006). Promoting self-determination in young children with disabilities: The critical role of families. Infants \& Young Children, 19, 338-352.

Shriner, M., Schlee, B., Hamil, M., \& Libler, R. (2009). Creating teachers' perceptual, behavioral, and attitudinal change using 
professional development workshops. Teacher Development, $12,125-134$.

Silva, L., Bowers, E., \& Lerner, R. (2010). One good thing leads to another: Cascades of positive youth development among American adolescents. Development and Psychopathology, 22, 759-770.

Sima, A., Wehman, P., Chan, F., West, M., \& Luecking, R. (2015). An evaluation of risk factors related to employment outcomes for youth with disabilities. Career Development and Transition for Exceptional Individuals, 38, 89-100.

Simonsen, M., \& Neubert, D. (2013). Transitioning youth with intellectual and other developmental disabilities: Predicting community employment outcomes. Career Development and Transition for Exceptional Individuals, 36, 188-198.

Smith, E. (2006). The strength-based counseling model. The Counseling Psychologist, 34, 13-79.

Smith, W., \& Zhang, P. (2009). Student's perceptions and experiences with key factors during the transition from high school to college. College Student Journal, 43, 643-657.

Solberg, S., Howard, K., Gresham, S., \& Carter, E. (2012). Quality learning experiences, self-determination, and academic success: A path analytic study among youth with disabilities. Career Development and Transition for Exceptional Individuals, 35, 85 .

Test, D., Mazzotti, V., Mustian, A., Fowler, C., Kortering, L., \& Kohler, P. (2009). Evidence-based secondary transition predictors for improving post-school outcomes for students with disabilities. Career Development for Exceptional Individuals, $32,160-181$.

The 2020 Federal Youth Transition Plan: A Federal Interagency Strategy. Author(s) (2015).

The Study Group, Inc. (2007). An assessment of transition policies and practices in state vocational rehabilitation agencies. Kill Devil Hills, NC: Author.

Tilson, G. \& Cuozzo Stern, L. (2001). Positive Personal Profile. Rockville, MD: TransCen.

Tilson, G., \& Hathaway, S. (2010). Learning to achieve: A review of the research literature on employment experiences and outcomes for youth and adults with learning disabilities. Retrieved from http://lincs.ed.gov/publications/pdf/L2A WorkforceLitReview2010.pdf

Tilson, G., \& Simonsen, M. (2013). The personnel factor: Exploring the personal attributes of highly successful employment specialists who work with transition-age youth. Journal of Vocational Rehabilitation, 38, 125-137.

Tilson, G. (2015). The Opportunity Game: How to Present Yourself as a Viable Job Candidate. Retrieved from http://vcurrtc. org/training/webcastDetails.cfm/323

Tilson, G. (2015). "Supporting Teenagers with Mental Health Issues." Presentation at the Konferanse InkluderingsKompetanse, Oslo, Norway, August 28, 2015.

Timmons, J., Hall, A., Bose, J., Wolfe, A., \& Winsor, J. (2011). Choosing employment: Factors that impact employment decisions for individuals with intellectual disability. Intellectual and Developmental Disabilities, 49, 285-299.

Trainor, A., Lindstrom, L., Simon-Burroughs, M., Martin, J., \& Sorrells, M. (2008). From marginalized to maximized opportunities for diverse youths with disabilities: A position paper of the Division on Career Development and Transition. Career Development for Exceptional Individuals, 31, 56-64.

Unger, D., \& Kregel, J. (2002). Employers' knowledge and utilization of accommodations. Work (Reading, Mass.), 21(1), 5-15.

U.S. Department of Education (2010). 29th annual report to Congress on the implementation of The Individuals with Disabilities Education Act, 2007, Volume 1. Washington, DC: Author.

van Velzen, J., van Bennekom, C., Sluiter, J., \& Frings-Dresen, M. (2015). Early vocational rehabilitation after acquired brain injury: A structured and interdisciplinary approach. Journal of Vocational Rehabilitation, 42, 31-40.

Ward, M. (2005). An historical perspective of self-determination in special education: Accomplishments and challenges. Research \& Practice for Persons with Severe Disabilities, 30(3), 108112.

Wehman, P. (2012). Supported employment: What is it? Journal of Vocational Rehabilitation, 37(3), 139-142.

Wehmeyer, M., Agran, M., Hughes, C., Martin, J., Mithaug, D. E., \& Palmer, S. (2007). Promoting self-determination in students with intellectual and developmental disabilities. NewYork: Guilford Press

Zander, R., \& Zander, B. (2000). The art of possibility: Transforming professional and personal life. Boston: Harvard Business School Press. 